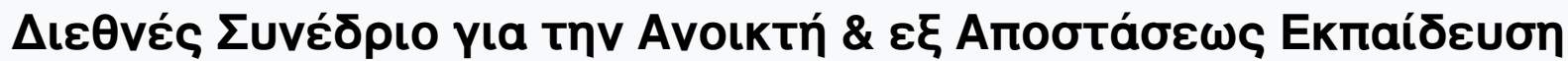

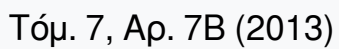

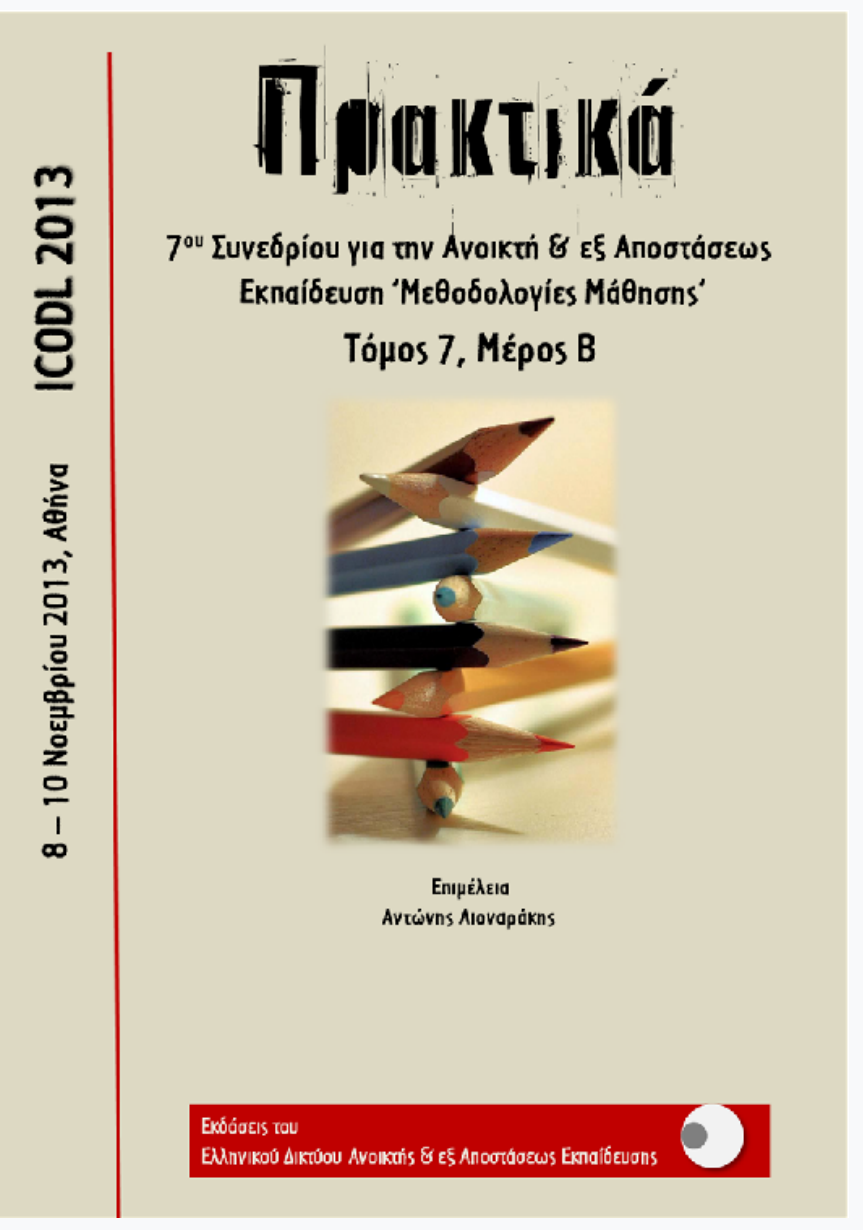

Increasing Motivation Through Gamification in ELearning

Kalliopi Rapti

doi: $10.12681 /$ icodl. 640 


\title{
Increasing Motivation Through Gamification in E-Learning
}

\author{
Kalliopi Rapti \\ LLEARN Educational Services \\ www.llearn.gr \\ info@llearn.gr
}

\begin{abstract}
Although e-learning efficiently deals with many problems that traditional learning environments face, it still copes with dull content which demotivates learners from progressing through syllabus. Gamification is a new trend that could help address this issue and this paper aims to describe its effective application.
\end{abstract}

Keywords: gamification, e-learning, distance learning, student motivation, educational technology

\section{Introduction}

E-learning already contains many game elements (Lee \& Hammer, 2011), like grades, points translated to "badges" and "upleveling" at the end of the every academic year. Given the existence of these elements, normally an e-learning course should already be gamified. Nonetheless, despite the inherent game-like experience of e-learning environments, these are still challenged by unmotivated students, because they are presented with mundane activities, while at the same time they thrive in video games, in terms of motivation and engagement, according to McGonigal (2011) . For this reason, e-learning is ripe for gamification, which, as a strategic process, can make the same activities be perceived more like a game, by making technology more engaging, and by encouraging desired behaviours, taking advantage of human psychological predisposition to engage in gaming, as proposed by Radoff (2011), thus increasing motivation.

\section{Definition of gamification}

Gamification is a new word, coined by Nick Pelling in 2002 for an old concept, that of games supporting (learning) objectives, which have been popular through the ages. Michael Wu defines it as the use of game mechanics to drive game-like engagement and actions, whereas Deterding, Dixon, Khaled and Nacke describe it as the use of game elements in a non-gaming context. So, fundamentally gamification is "the use of game-based mechanics, aesthetics and game thinking to engage people, motivate action, promote learning, and solve problems" (Kapp, 2012).

The definition of what gamification is not is of equal importance, as shown in Fig. 1. Since it derives from the word "game", it is not related to play, following the distinction between paidia and ludus, where the former is more informal and allows experimentations, and the latter is more structured on rules and goals. Therefore gamification shouldn't be confused with serious games (Gåsland, 2011), an aspect of game-based learning. Serious games serve a pedagogical purpose by using game properties towards this purpose, thus they are still considered a game but with an 
educational context. They are also developed by game designers and come in the form of simulations. When using gamification you are not in a virtual world but in the real one.

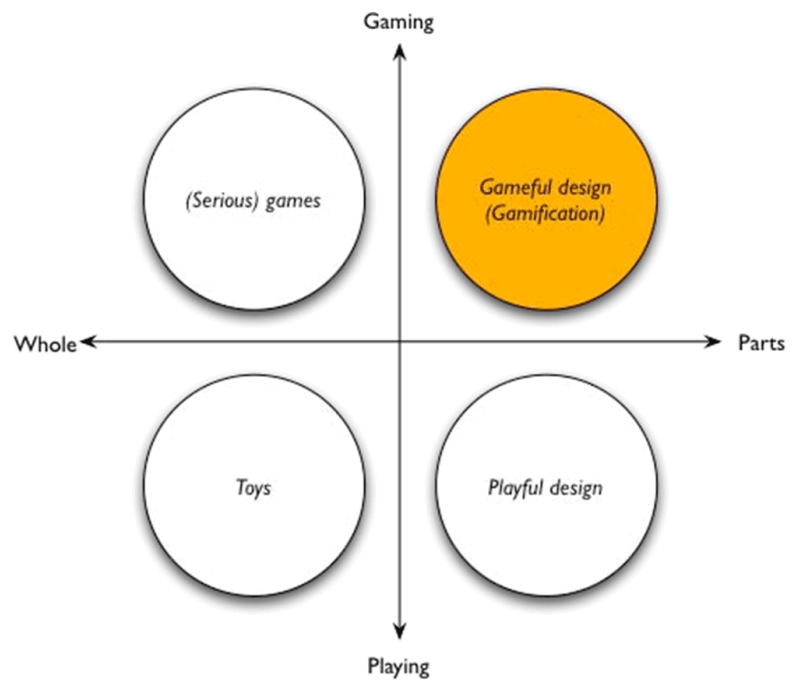

Fig. 1 Towards a definition of gamification (Deterding et al.)

Gamification comprises of game mechanics, which are the basic processes, and rules, which gamify an activity, like points, chalenges, leaderboards, levels, virtual goods and gifts, that in turn lead to motivations of the experience, i.e., game dynamics, such as rewards, achievement, competition, status, self-expression, and altruism.

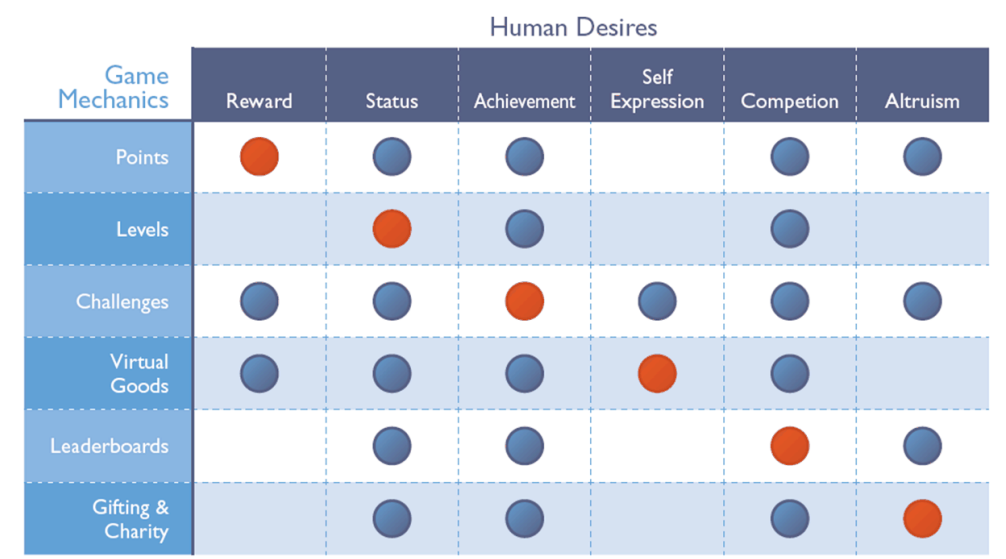

Fig. 2 The interaction between basic human desires and game play. The red dots signify the primary desire a particular game mechanic fulfills, and the blue dots show the additional areas that it affects (www.bunchball.com).

According to Kapp, there are two types of gamification: "Structural and Content". The former gamifies the structure around the content, which remains unchanged, in order to incentivize the learner to go through the content by rewarding their progress. The latter aims to change the context itself by making it more game-like. Structural gamification can be used more effectively for motivating learners to move through or return to the curriculum, whereas content gamification is more useful for introducing new knowledge. Of course, these two types can be combined, leading to even greater motivation and engagement. 


\section{Is gamification applicable to e-learning?}

The e-learning environment is ideal for the application of gamification due to its inherent virtual and intangible nature, just like gamification itself. E-learning provides an already more engaging and motivational infrastructure than traditional classrooms, where gamification can be incorporated in order to raise even higher engagement and motivation. More specifically, the pedagogical limitations of an e-learning system are another reason why gamification could prove beneficial. Usually, e-learning courses lack emotional interaction and fail to stimulate learners as a teacher could possibly do. Gamification could fill in for this lack of feeling. Moreover, the fact that most elearning courses are linear makes the implementation of gamification even easier, e.g., "by revealing content gradually and progressively" (Muntean, 2011). We should bear in mind that the focus of any e-learning project is on the content, which it can somehow prove dull, and that is why gamification can supplement and reinforce the material. Nonetheless, content should be a priority and game elements supplemental. Lastly, the narrative style of an e-learning course allows for the inclusion of game mechanics without compromising them.

\section{Ways of applying gamification to e-learning}

One approach is the transformation of the whole experience into a more game-like one through the use of game mechanics, proving rewards to learners that display desired behaviors (Erenli, 2012). We can use:

- Points in order to reward learners for progressing within the content, for great perfomance or even for continuous engagement and for unlocking access, e.g., to the next chapter

- Levels as point thresholds and indicators of the learner's progression throughout a course and leveling-up according to accomplishment

- Badges, which are intangible rewards that recognize accomplished missions, achieved milestones and even completed levels.

- Leaderboards, which display learners' progression and achievements against others, triggering competition or inspiring desired actions.

Another approach is the satisfaction of the fundamentally universal above-mentioned desires, through the use of game dynamics, such as:

- Status, accomplished by the afore-mentioned game mechanics and satisfying human desire for respect and prestige.

- Self-expression, by providing learners with a fully customizable avatar, meeting their need to display unique identity features and originality.

- Competition, because humans feel satisfaction when they compare their performance to others, through the public display of the learners' points, badges etc.

- Altruism, by receiving and sending gifts which in turn incentivize learners to enter an engagement loop that serves as a retention tool.

All these can be used individually or simultaneously, but in order to be effective and to motivate learners, they should create a "flow" experience, where the learner is completely absorbed and engaged in the activity. So, according to Csikszentimihalyi, the learner should have autonomy over his actions and be provided with feedback, have defined goals and concentration free from distraction. 


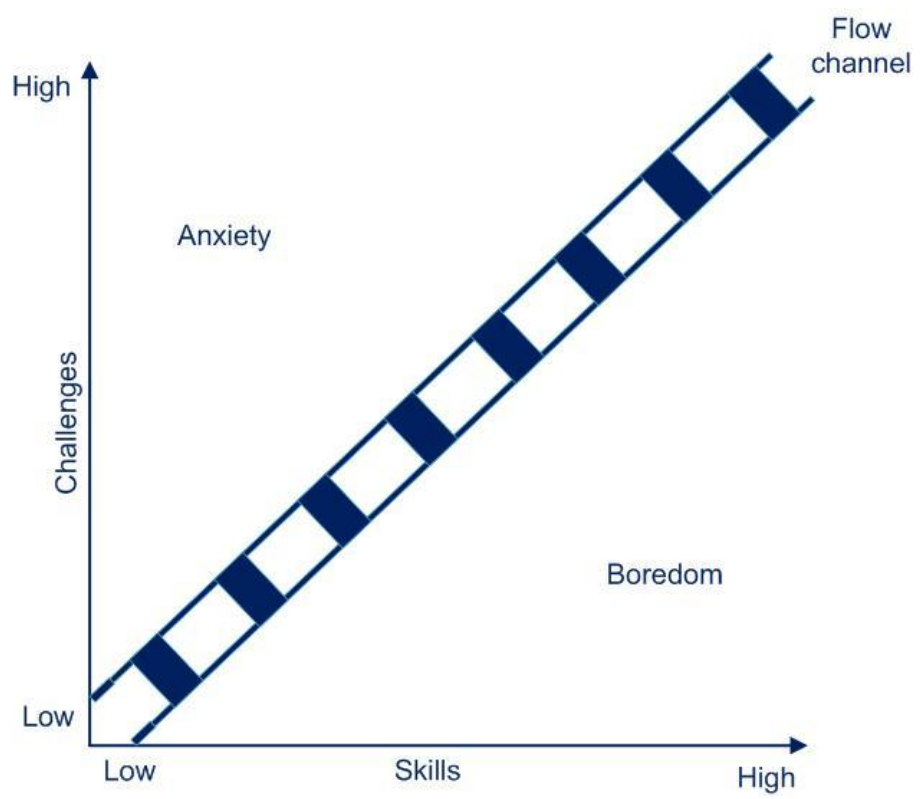

Fig. 3 Csikszentmihalyi's chart and the flow channel.

Moreover gamification shouldn't be all about points, it should also be meaningful; it shouldn't be completely without points, otherwise it will be just play. The integration of game mechanics and dynamics should make sense and be all harmonically tied together. In addition, progress, learning goals, and the way each game element is appointed should all be transparent, as Nicholson (2012) correctly proposes.

\section{Examples of application of gamification}

KhanAcademy (www.khanacademy.org) is a nonprofit educational organization, an online education site that uses game elements to keep learners motivated to complete courses. It includes 100 self paced exercises, 1,800 lessons and 2,100 videos not only on traditional academic subjects like physics, but also historical or current events. Subjects are visually organized as a constellation on a Google map so that lessons are arranged in a logical sequence as a chain. The learner is rewarded for opening up a challenge or for quick problem solving. It also remembers and quantifies your progress every time you login.

Lee Sheldon at the University of Indiana and Rensselaer Polytechnic, gives experience points to his students instead of grades. Normally you start with an A and then depending on what you do you move down towards an F. In a game you start at zero points and you work your way up. So, he implemented the system that way.

Another dimension is the credentialing function. You can confirm you have specific skills by your official diploma or degree. But what about things that you learned outside of the traditional formal educational system? For these reasons, the Mozilla Foundation launched the Open Badge framework (http://openbadges.org/), where the game elements of badges are used as a way of confirming certain skills and accomplishments, that come from informal, social or/and lifelong learning.

\section{Reasons for using gamification in e-learning}

The implementation of gamification in e-learning has some apparent benefits. It raises engagement, motivation, attainment and retention, while at the same time improves personal learning and thinking skills. It can build up teams through collaboration and increase performance through competition. In addition, it can improve the quality of teaching and increase digital literacy. In terms of emotion, games can bring about a 
variety of emotions, from disappointment to happiness and from sorrow to pride. But the most interesting case of emotional transformation involves the feeling of failure. In a purely exclusive game environment, players have the "freedom to fail" (Osterweil, 2007). They can explore the game, experiment with its different areas, yet they are not afraid they might cause irreversible damage, because they have, for example, multiple lives. In the same way, learners should be encouraged to proceed with their learning without fear of failing, and not to focus on end results. As Kapp notes, this means "encouraging learners to explore content, take chances with their decision making, and be exposed to realistic consequences for making a wrong or poor decision", or as Lee and Hammer put it, teachers should "maintain this positive relationship with failure by making feedback cycles rapid and keeping the stakes low".

\section{Conclusion}

Games are known to thrive in terms of engagement. Teachers already use game elements in their curriculum successfully. This paper has attempted to introduce the concept of gamification and its implementation to an e-learning environment due to its obvious benefits. Nonetheless, gamification should be implemented carefully in order to have the desirable results and should not be consider as a cure for everything, despite its immense popularity.

\section{Bibliographic References}

Csikszentmihalyi, M. (2009). Creativity: Flow and the Psychology of Discovery and invention (pp 111115). HarperCollins.

Deterding, S., Dixon, D., Khaled, R., \& Nacke, L. (2011, September). From game design elements to gamefulness: defining gamification. In Proceedings of the 15th International Academic MindTrek Conference: Envisioning Future Media Environments (pp. 9-15). ACM.

Erenli, K. (2012, September). The impact of gamification: A recommendation of scenarios for education. In Interactive Collaborative Learning (ICL), 2012 15th International Conference on (pp. 1-8). IEEE

Gamification 101: An Introduction to the Use of Game Dynamics to Influence Behavior. Retrieved 29/06/13, from http://www.bunchball.com/gamification/g101-list.shtml.

Gåsland, M. (2011). Game mechanic based e-learning. Science And Technology, Master Thesis (June 2011). Available at: http://ntnu. diva-portal. org/smash/get/diva2, 441760.

Kapp, K. M. (2012). The gamification of learning and instruction: game-based methods and strategies for training and education ( $\mathrm{p} 10)$. Pfeiffer.

Kapp, K. M. (2013). Two Types of Gamification. Retrieved 29/06/13, from http://www.ulqcl.com/kappnotes/index.php/2013/03/two-types-of-gamification/.

Lee, J. J., \& Hammer, J. (2011). Gamification in education: What, how, why bother?. Academic Exchange Quarterly, 15(2), 146.

McGonigal, J. (2011). Reality is broken: Why games make us better and how they can change the world. Penguin books.

Muntean, C. I. (2011, October). Raising engagement in e-learning through gamification. In Proc. $6^{\text {th }}$ International Conference on Virtual Learning ICVL (pp. 323-329).

Nicholson, S. (2012). A user-centered theoretical framework for meaningful gamification. Proceedings $G L S, 8$.

Osterweil, S. (2007). Designing Learning Games that Matter. The Education Arcade: MIT.

Pelling, N. (2011). The (short) prehistory of "gamification". Retrieved 17/06/12 from http://nanodome.wordpress.com/2011/08/09/theshort-prehistory-of-gamification/

Radoff J. On, G. (2011). Energize Your Business with Social Media Games.

Sheldon, L. (2012). The Multiplayer Classroom: designing coursework as a game. Course technology.

$\mathrm{Wu}$, M. (2011). Gamification from a company of pro gamers. Retrieved 29/06/12 from http://lithosphere.lithium.com/t5/science-of-social-blog/Gamification-from-a-Company-of-Pro Gamers/ba-p/19258. 